\title{
A SIMULATOR STUDY OF RECOVERY OF HVDC LINKS FOLLOWING AC SYSTEM FAULTS
}

\author{
J. Senthil, K.R. Padiyar, \\ Department of Electrical Engineering, \\ Indian Institute of Science, Bangalore 560012 \\ Sachchidanand, \\ Department of Electrical Engineering, \\ Indian Institute of Technology, \\ Kanpur 208016
}

\begin{abstract}
This paper presents the simulator study of a two-terminal HVDC system. The various AC system faults to which the study system is subjected are a) remote-three-phase ground fault, b) single-phase-ground fault and c) threephase-ground faults. These faults are applied both at the rectifier and inverter ends. The results of the simulator study are presented to demonstrate the controller performance in the recovery of HVDC link following AC system faults.
\end{abstract}

\section{INTRODUCTION}

High Voltage Direct Current (HVDC) has emerged as a viable alternative to AC for long distance bulk power transmission and interconnection of power systems. The economic design and optimal operation of a HVDC system requires the detailed investigation of the dynamic performance of the system both under steady state and transient conditions. The tools which are commonly employed for investigating the dynamic behaviour of the HVDC system are i) HVDC simulator (physical models) and ii) digital simulation programs. Although digital simulators offer significant benefits in terms of cost and flexibility, HVDC simulators on the other hand offer distinctive advantages in terms of realistic controlier models and real time simulation.

This paper presents the simulator study of the recovery of a two-terminal HVDC link following AC system faults. The HVDC simulator available at the central Power Research Institute (CPRI) Bangalore, is used for this purpose.

\section{SYSTEM DESCRIPTION}

The one-1ine diagram of the system under study, adapted from [1], is shown in Fig.1. The system under study is a monopolar, 12-pulse system, in which, the rectifier as weil as the inverter terminals are represented. The AC network supplies the converter through two converter transformers, one with wye-wye connection and the other with wye-delta connection. In order to suppress harmonics, filters are provided both on the $A C$ and $D C$ sides of the converter.

$$
\begin{gathered}
\text { DESCRIPTION OF SYSTEM MODELS IN THE } \\
\text { SIMULATOR . }
\end{gathered}
$$

The HVDC simulator available at CPRI, is a scaled down model of a HVDC plant and has the capability to model a bipolar HVDC transmission system. The DC simulator consists of miniature models of converter transformers, 12-pulse converter units and a large number of inductors with provision for external connection of resistors and capacitors to enable the modelling of transmission lines and filter circuits. The synchronous generator is represented by analog electronic circuit models. The simulator is rated $8 \mathrm{~W}$ and $40 \mathrm{~V}$ per 12-pulse converter. This low power level makes it possible to use electronic circuits to compensate for the losses in order to obtain the simulation of realistic systems.

The HVDC simulator has full size plant control system, which includes the converter control and pole control. The functions of the converter control are to generate and control firing pulse to the thyristor valves, to provide converter protection and to start and stop the converter in the correct sequence. The pole control in addition to generating the current order, provides protection at the pole level. The hardware of the converter and poln control is realised by using programmable micro-computers.

A detailed description of the various facilities available on the simulator are described in [2], while the models employed for this study are given in [3].

\section{SCALING PROCEDURES ON THE SIMULATOR}

To represent an actual system or station on the simulator, all station quantities need to be scaled down to simulator quantities using the relation

Station quantity $* S=$ Simulator quantity

where $S$ is the relevant scaling factor

For the purpose of scaling, the entire HVDC network can be divided into 7 regions. These regions are:

1.AC network and filter (rectifier)

2. Converter transformer, network side(rectifier) 3. Converter transformer, valve side (rectifier) 4.DC side - this includes the smoothing inductors, DC line, and the DC filters. 5. Converter transformer, valve side (inverter) 6. Converter transformer, network side(inverter)

7.AC network and filter (inverter)

The simulator has the following ratings or base values:

line-to-line AC voltage: $10 \sqrt{3} \mathrm{v} r \mathrm{~ms}$ DC voltage per 12-pulse converter: $40 \mathrm{~V}$ DC current per 12-pulse converter: $200 \mathrm{~mA}$ DC power per 12-pulse converter : $8 \mathrm{~W}$ The scaling factors of power, voltage, 
current and impedance (denoted as $\mathrm{s}_{\mathrm{p}}, \mathrm{s}_{\mathrm{v}}, \mathrm{s}_{\mathrm{i}}$ and $S_{z}$ respectively) calculated using equn. (1) for the different regions of the study system of fig. 1 are given in Appendix-B.

\section{STUDIES PERFORMED ON THE HVDC SIMULATOR}

The various AC system faults to which the study system is subjected are remote threephase-ground fault, single-phase-ground fault and three-phase-ground fault at the converter bus. These faults are applied both at the rectifier and inverter side. These studies were carried out by using the actual HVDC controllers available on the simulator.

\section{RESULTS AND DISCUSSIONS}

For each of the transient case considered above, plots of a)rectifier firing angle, rectifier DC current, rectifier DC voltage, rectifier bus voltage (A-phase), and b)inverter gama, inverter DC current, inverter DC voltage, inverter bus voltage (A-phase) are given. It is to be noted that for each fault case considered below, the rectifier and inverter side plots were not recorded at the same instants of time. Also, in obtaining these plots, a point on the wave selector was not used.

\section{Remote-Three-Phase-Ground Fault}

A remote three-phase-ground-fault was simulated by grounding all the three phases of the converter AC bus through 100 ohm resistances. The duration of the fault was 10 cycles. This fault was applied at the rectifier and inverter ends.

Remote-three-phase-ground fault at rectifier

Results of this transient study are shown in figs. 2 and 3 . When the fault is applied, die to a reduction in the rectifier $A C$ bus voltage, the rectifier DC voltage and hence the DC current decrease. The current controller of the rectifier, in an attempt to increase the current, reduces its firing angle and hits the minimum. limit. Due to reduction in the DC current, the inverter current controller takes over. During the faulted period, the DC current settles down at an average value as determined by VDCOL. When the fault is cleared after 10 cycles, the rectifier current controller takes over and the inverter resumes extinction angle control. The steady-state is reached within 4 cycles after the transients during which there is an overshoot of DC current. overvoltages upto 1.2 pu are observed on the AC voltages of rectifier bus during recovery. The DC currents and voltages settle at their pre-fault values after the fault is removed.

\section{Remote-three-phase-ground fault at inverter}

The results of this study are shown in figs. 4 and 5. When the fault is applied, due to a reduction in the receiving end DC voltage, the DC current shoots up. The rectifier, in an at tempt to control the current, is transiently driven into the inverter region. The DC current then reduces to a low average value under the action of vDCOL. During the faulted period, there are overvoltages at the rectifier bus. When the fault is cleared after 10 cycles, due to an increase in the inverter $A C$ bus voltage, the DC voltage of the inverter momentarily increases ana hence the DC current decreases.
The rectifier current controller attempts to increase the DC current by decreasing the rectifier alpha. The recovery from the fault is slowed down due to a commutation failure, during which the inverter DC voltage decreases and hence the DC current shoots up. overvoltages upto $1.4 \mathrm{pu}$ and $1.2 \mathrm{pu}$ appear on the AC voltages of the rectifier and inverter bus respectively. Thereafter, the DC voltage and currents increase and settle down at their prefault values.

\section{Single-Phase-Ground Fault}

A single-phase-ground fault was applied to the A-phase of the converter bus. This fault was applied both at the rectifier and inverter ends, and the duration of the fault was 10 cycles.

\section{Single-phase-ground fault at rectifier}

The results of this study are shown in figs. 6 and 7 . When this fault is applied, the AC voltage of the rectifier bus (A-phase) reduces to zero (seefig. 6d). The rectifier DC voltage and hence the DC current also reduces. The rectifier current controller attempts to increase the DC voltage by reducing the firing angle of the rectifier. The inverter takes control of current and the inverter gama therefore increases (see fig. 7a). Since only one phase of the rectifier AC bus is faulted, the resulting unbalance in the phase voltages on the rectifier $A C$ bus generates second harmonic oscillations in the $D C$ voltages and currents. Due to this, oscillations appear in the rectifier firing angle and the inverter gama also. When the fault is cleared after 10 cycles, due to the sudden increase in the rectifier AC bus voltage, the rectifier $D C$ voltage and consequently the current increases. The current controller at the rectifier attempts to reduce the current by increasing its firing angle. During the post-fault period. distortions appear in the AC voltages of rectifier as well as the inverter bus. The recovery is slowed down by the occurrence of a single commutation failure at the inverter.

Single-phase-ground fault at inverter

Results of this study are shown in figs. 8 and 9. When this fault is applied, due to a reduction in the AC voltage of the inverter bus, the inverter DC voltage decreases. The DC current therefore shoots up. The rectifier current controller attempts to reduce the current by increasing its firing angle and the rectifier therefore goes into the inverter region. The DC current decreases to a low average value as determined by the vDCOL. The AC voltages of the rectifier are distorted and attain peak values upto 1.4 pu. After the fault is cleared, at about $t=0.35 \mathrm{sec}$, although the inverter DC voltage (fig. $9 \mathrm{C}$ ) shows that it has recovered, the rectifier DC voltage (fig.8c) -strows a dip due to a commutation failure at the inverter. This anomaly is because of the fact that the rectifier and inverter side plots were not recorded at the same instant of time and also because, a point-on-the wave selector was not used.

Three-Phase-Ground Fault

A three-phase-to-ground fault was applied 
to the converter AC bus. This fault was applied both at the rectifier and inverter ends.

\section{Three-phase-ground fault at rectifier}

The results of this study are shown in figs. 10 and 11 . After this faul is applied, the DC current goes to zero. When the fault is cleared after 4 cycles, the recovery is slow and there are oscillations in the DC current and voltage. The rectifier bus voltages are distorted and overvoltages upto 1.4 pu appear on them.

Three-phase-ground fault at inverter

The rectifier and inverter side plots for this study are shown in figs. 12 and 13 respectively. In obtaining the rectifier plots, the fault duration was 10 cycles, while in obtaining the inverter plots, the fault duration was 4 cycles.

When the fault is applied, due to a sudden reduction in the inverter DC voltage, there is overshoot in DC current of magnitude 2.5 pu. The rectifier current controller attempts to reduce the DC current by increasing the firing angle of the rectifier. The rectifier therefore goes into the inverter region. The $\mathrm{DC}^{2}$ current reduces to a low average value as determined by the VDCOL. The rectifier AC voltage is distorted and overvoltages upto 1.4 pu appear on them. During the faulted period, the rectifier $D C$ voltage oscillates about zero value. After the fault is cleared, the rectifier DC voltage transiently reverses due to commution failure at inverter. The rectifier DC voltage and current oscillate and settle at the pre-fault values in about 12 cycles after the fault is cleared.

\section{Discussion of the results}

From the results given above it can be seen that, in the case of remote-three-phaseground faults and single-phase-ground faults at rectifier, a reduced but finite amount of DC power is transmitted even during the faulted period. Unbalanced faults on the rectifier side leads to a significant increase in the second harmonic component on the DC side.

Fauls on the inverter end leads to a reduction in the receiving end voltage. This causes an initial overshoot in the DC current. Depending on the severity of the fault, the inverter undergoes one or more commutation failures. The system however recovers after the fault is cleared.

During normal operation, the rectifier is under current control mode and the inverter under extinction angle control mode. During faults, when the DC currnt reduces below the current reference of the inverter, the inverter takes control of current. After the fault is cleared, the current control is transferred back to rectifier.

In general, the recovery of the DC link from inverter side faults can be problematic. The most severe fault is the three phase fault. The converter controller has to be properiy tuned to speed up recovery from the fault. The speed of recovery is also dependent on the short circuit ratio at the inverter.
It is to be noted that no attempt was made to tune the controller parameters for the system under study. The default controller parameters provided on the simulator were instead used.

\section{CONCLUSIONS}

The simulator study of a two-terminal HVDC link is decribed. The results presented demonstrate the controller performance in the recovery of the HVDC link following AC system faults.

\section{ACKNOWLEDGEMENT}

The facilities and the help provided by the authorities of cPRI Bangalore in carrying out these studies is gratefully acknowledged.

\section{REFERENCES}

1. S. Bhattacharya, 'Simulation of Transient Phenomena in High Voltage Direct-Current Converter Systems', Ph.D Thesis, The Univ. of British Columbia, Canada, March 1987.

2. M.M. Babunarayanan, "CPRI HVDC Simulator" Proceedings of the National Workshop on HVDC Transmission, Kanpur, India, Jan, 14-16,1987, pp. $5.1-5,23$.

3. J. Senthil, 'simulation of Transients in Synchronous Generators and HVDC Links and Study of Torsional Interactions', Ph.D Thesis submitted to Dept. of Electrical Engg., I IT Kanpur, India, September, $19 y 0$.

4. G. Andersson, S.Svensson and G.Liss, 'Digital and Analog Simulation of Integrated $A C$ and DC Systems', Paper 14-02, CIGRE meeting, Paris, 1982 .

\section{APPENDIX - A}

I. 2-Termina1 System Data [1]

a) DC Line Parameters

Resistance $(\Omega / \mathrm{mile})=0.0062$
Inductance $(\mathrm{mH} / \mathrm{mile})=0.70789$
Capacitance $(\mu \mathrm{f} / \mathrm{mile})=0.04183$
Length of line $(\mathrm{mlles})=489$

b) Converter Transformer Parameters

$\begin{array}{lcc}\text { Leakage inductance }(\mathrm{mH}) & \frac{\text { Rectifier }}{27.23} & \frac{\text { Inverter }}{27.23} \\ \text { Winding Resistance }(\Omega) & 0.025 & 0.025 \\ \text { Nominal voltage ratio } & 345 / 206.2 & 500 / 202.4 \\ \text { c) AC System Parameters } & & \\ & \frac{\text { Rectifier }}{172.0} & \frac{\text { Inverter }}{128.8} \\ L_{a}(\mathrm{mH}) & 3.97 & 1.30 \\ \mathrm{R}_{\mathrm{sr}}(\Omega) & 2917.6 & 687.5 \\ \mathrm{R}_{\mathrm{a}}(\Omega) & 1.36 & 3.45 \\ \mathrm{C}_{\mathrm{a}}(\mu \mathrm{f}) & \end{array}$

d) AC/DC operating Conditions

$\begin{array}{lcc}\text { Firing angle } & \text { Rectifier } & \text { Inverteg } \\ \text { extinction angle } & 150 & 153^{\circ} \\ \text { DC Current (kA) } & 170 & 17 \\ \text { Short Circuit Ratio } & 1.6 & 1.6 \\ \text { DC Voltage (kV) } & 2.21 & 6.03 \\ \text { RMS Voltage of Converter } & 5104.81 & 505.15 \\ \text { bus (kV) } & \end{array}$

Scaling factors for the study system of fig. 1 
The power voltage current and impedance scaling factors for the different regions of the system of fig. 1 are given below:

Region 1: $s_{p 1}=10^{-8}, s_{v 1}=0.00005, s_{i 1}=0.0002$ Region 2 : $S_{p 2}=S_{p 1}, S_{v 2}=S_{v 1}, S_{i 2}=S_{i 1}, S_{z 2}=S_{21}$ Region $3: s_{p 3}=S_{p 1}, s_{v 3}=0.00008, s_{i 3}=0.000125$, Region $4: S_{p_{4}}=S_{p_{1}}, S_{v 4}=S_{v 3}, S_{i 4}=S_{i 3}, S_{24}=S_{23}$ Region 5 : $S_{\mathrm{p} 5}=\mathrm{S}_{\mathrm{p} 3}, \mathrm{~S}_{\mathrm{v}}=\mathrm{S}_{\mathrm{v}}, \mathrm{S}_{\mathrm{i} 5}=\mathrm{S}_{\mathrm{i} 3}, \mathrm{~S}_{25}=\mathrm{S}_{z} 3$ Region $7: S_{p 7}=S_{p 1}, S_{v 7}=0.0000346, S_{i 7}=0.000289$ Region $6: s_{p 6}=S_{p 7}, S_{v 6}=S_{v 7}, S_{i 6}=S_{i 7}, S_{26}=S_{27}$

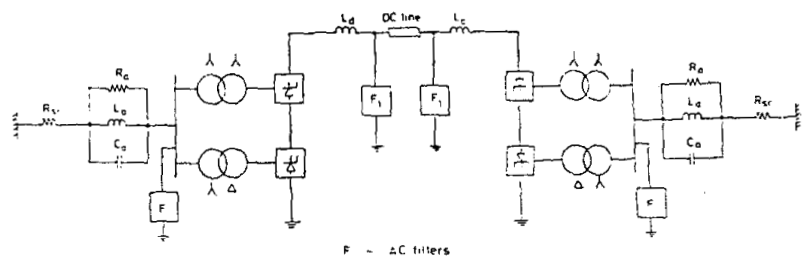

$$
\begin{aligned}
& F_{1}-2 C \text { witers } \\
& F_{1}-36 \text { tilters }
\end{aligned}
$$

Fig.

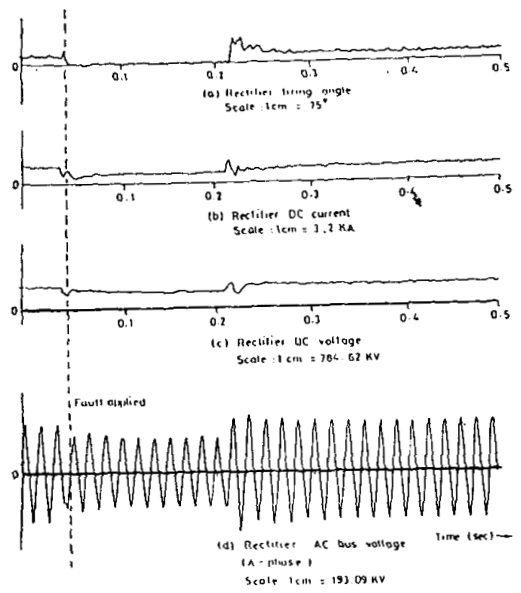

Fig. 2 Remole - three-phase -gricund laut at tectilier (ceclitier plots)

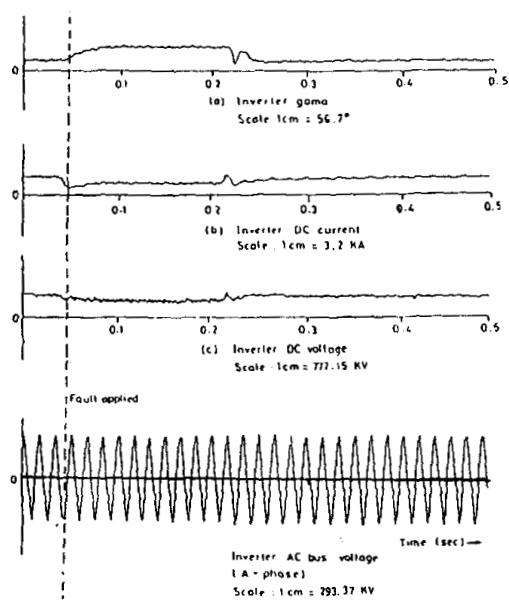

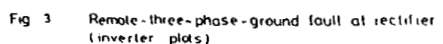
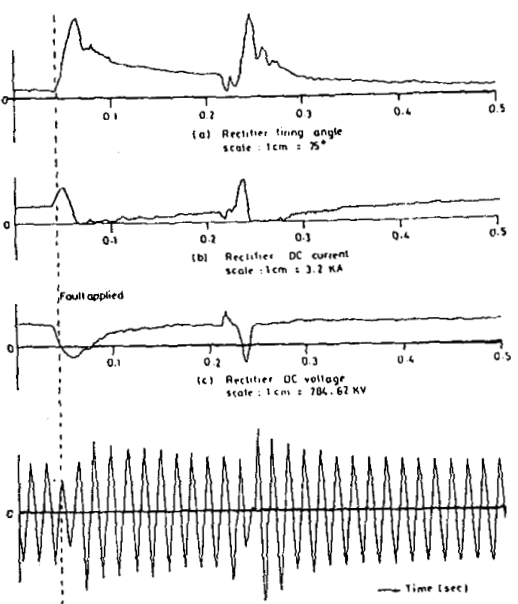

$$
\text { (d) Ratitier ac bus voltage }
$$

Srote: $\mathrm{KCm}=199.09 \mathrm{kY}$

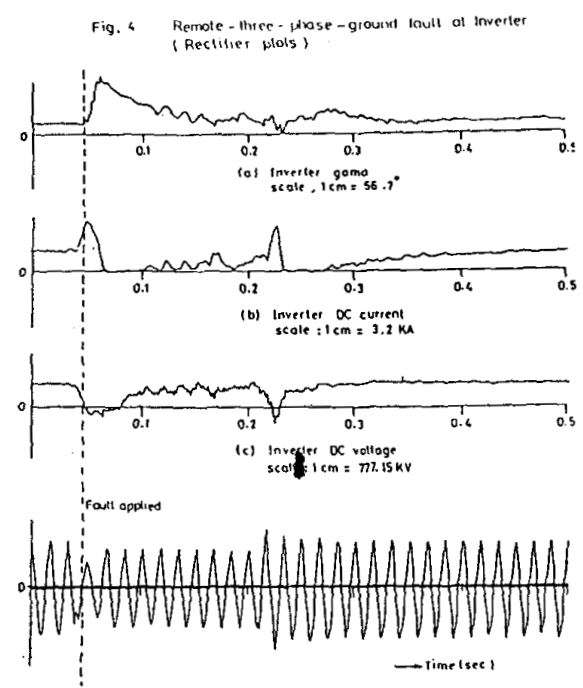

(d) Inverter ac bus vollage (A-pinese)
Scair $1 \mathrm{em}=293.37 \mathrm{~kW}$

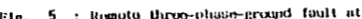
envarter (Inverter pluts)

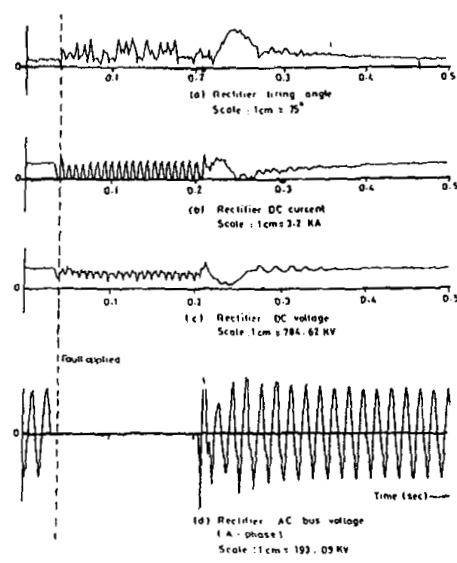
Fig. 6 Surgle- phase-ground taull at rectiliet 


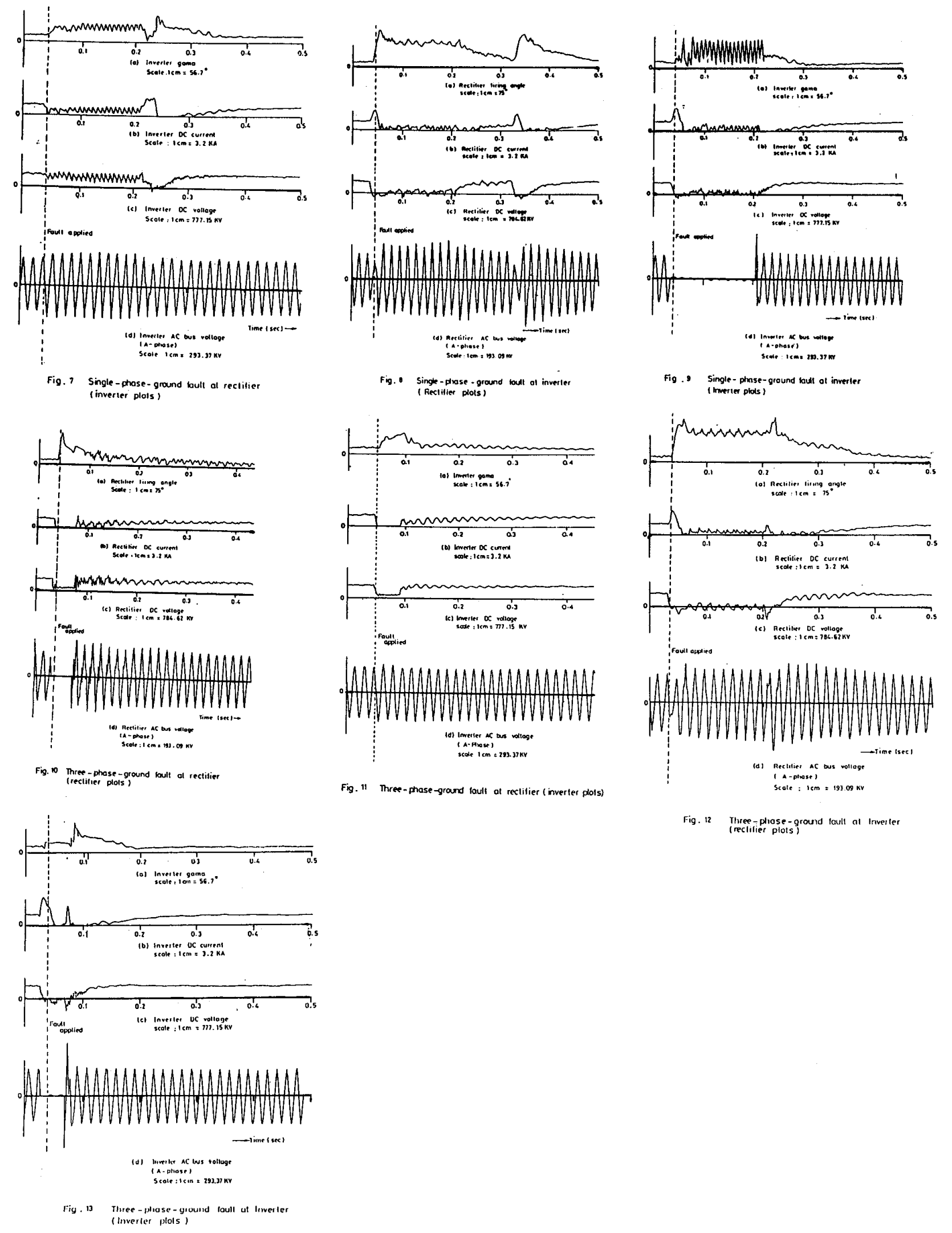

